\title{
Harvest Techniques for Hops (Humulus lupulus) ${ }^{1}$
}

\author{
Sean Michael Campbell and Brian J. Pearson²
}

\section{Introduction}

Hops (Humulus lupulus) are perennial plants that grow as tall bines, meaning they wrap around a vertical supporting structure during vegetative growth. They are commonly harvested for their mature strobiles, also referred to as cones (Figure 1), which are primarily dried and used as a bittering agent and preservative in beer production. Before this the cones must first be harvested from the bines. The two primary factors of harvest timing and harvest method can have large impacts on the quality and economics of the finished product.

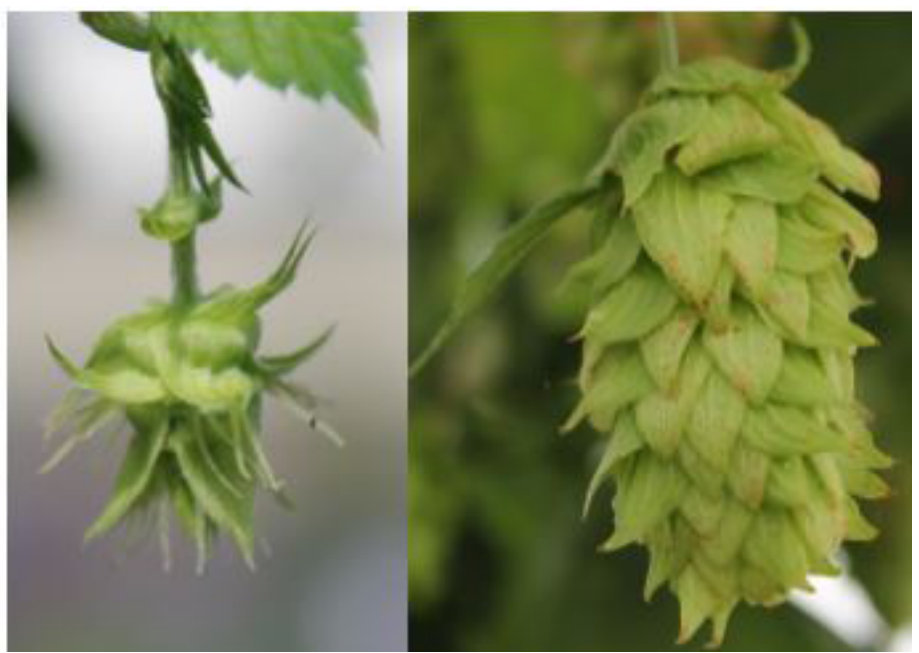

Figure 1. Hop cone formation. Left: Newly formed hop burr. Right: Mature hop cone.

Credits: Sean M. Campbell, UF/IFAS

\section{Harvest Timing}

Harvest timing depends on a variety of factors, from environmental conditions to the cultivar used. For most growing regions, a generalized hops production timeline can be used beginning in late June with formation of burrs (Figure 1). By late July these burrs form immature cones, which will continue to mature and lose moisture content through mid-August and into September. While this timeline is a good reference, harvest timing should be based off growing-region-specific environmental conditions combined with physical observations of the cones, primarily color and moisture content.

Hops can be harvested between August and September in most regions. Cones should be a deep green color with yellow lupulin glands visible between the bracts (Figure 2), and the aroma from the cones should be at its strongest. The best way to measure the maturity of a hop cone is moisture content, most commonly assessed in the field by rubbing a cone between fingers. Mature cones will have a dry papery sound and feel, with easy release of the yellow lupulin powder glands. Slight browning of the lower bracts is common and can be an indicator of maturity. Harvesting hops prematurely can result in excess moisture content of the cone, and hops that overmature can lose quality due to shattering and discoloration (Gorst Valley Hops n.d.). Both will result in an economic loss to the producer.

1. This document is ENH1314, one of a series of the Environmental Horticulture Department, UF/IFAS Extension. Original publication date December 2019. Visit the EDIS website at https://edis.ifas.ufl.edu for the currently supported version of this publication.

2. Sean Campbell, doctoral research assistant, and Brian Pearson, assistant professor, Environmental Horticulture Department, UF/IFAS Mid-Florida Research and Education Center, Apopka, FL 32703.

The Institute of Food and Agricultural Sciences (IFAS) is an Equal Opportunity Institution authorized to provide research, educational information and other services

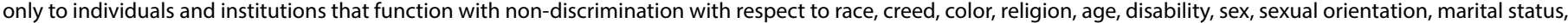
national origin, political opinions or affiliations. For more information on obtaining other UF/IFAS Extension publications, contact your county's UF/IFAS Extension office. U.S. Department of Agriculture, UF/IFAS Extension Service, University of Florida, IFAS, Florida A \& M University Cooperative Extension Program, and Boards of County Commissioners Cooperating. Nick T. Place, dean for UF/IFAS Extension. 


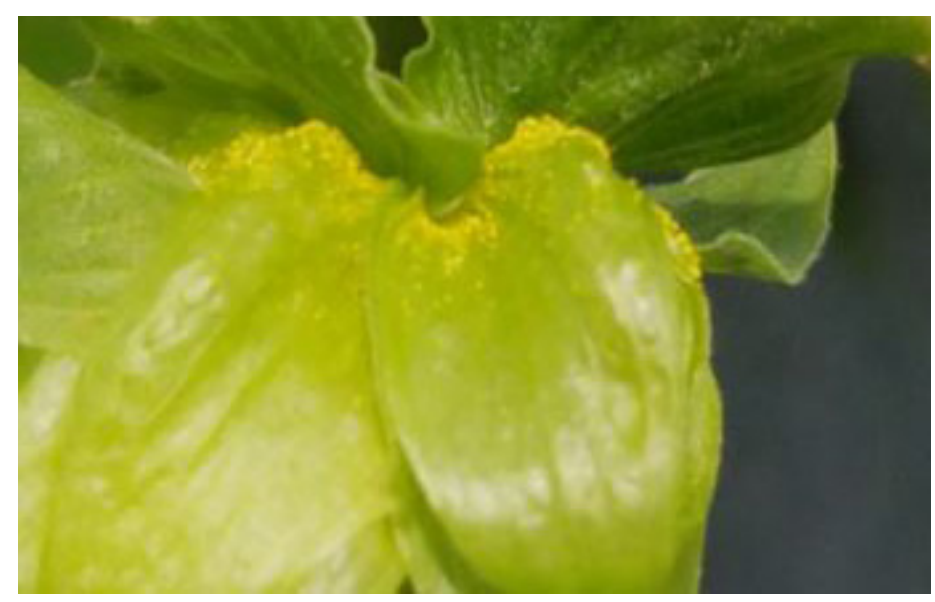

Figure 2. Bright yellow lupulin glands visible between the mature hop cone bracts.

Credits: Sean M. Campbell, UF/IFAS

\section{Single vs. Multiple Cultivars and Bines}

Another important consideration in the harvest timing of hops is the decision to use single vs. multiple cultivars per plot, as well as the use of single vs. multiple bines per string (Figure 3). The traditional practice in large hop production areas is to grow a single cultivar per plot.

During production the young plants are thinned to a single bine per string. This helps ensure that all the hop cones in a given plot will mature at the same rate; also, single bines are necessary if using mechanical harvesting. This option can be less than ideal for small-scale growers though, who may wish to optimize their production by diversifying with multiple cultivars. Using multiple cultivars per string can maximize yield and minimize labor by not thinning the young plants and leaving multiple bines per string. This can lead to multiple maturity periods among varieties and even among strings. It requires careful observation and multiple harvests over a longer period, but it potentially can increase overall yield (Carter et al. 2018).

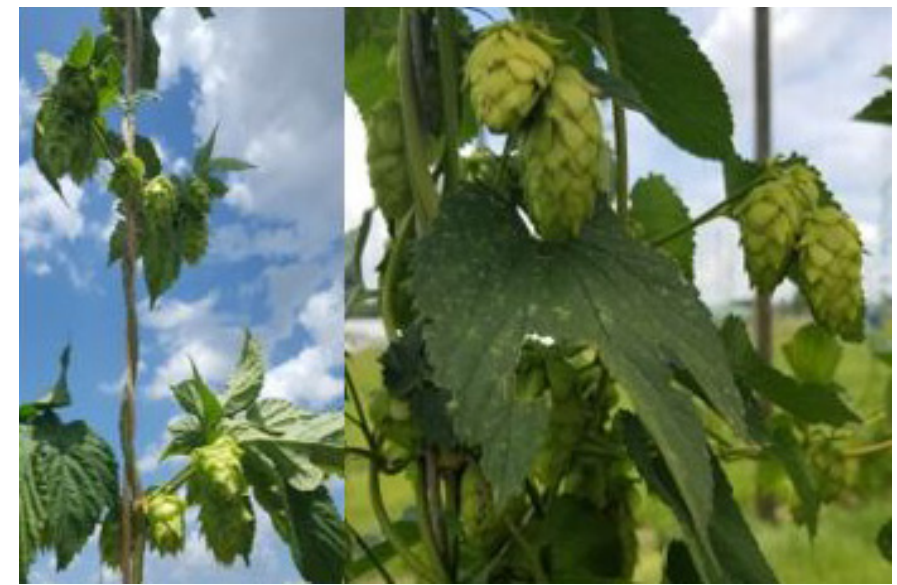

Figure 3. Left: Single bine per support string. Right: Multiple bines per support string.

Credits: Sean M. Campbell, UF/IFAS

\section{Harvest Method}

Once cones reach maturity, there is an optimal window of around 5 days on the bine where they should be harvested, or loss of cone quality will begin. Harvesting is one of the main costs in producing hops, and given this short window, selecting an appropriate harvest method is crucial. Two main harvest methods are commonly used, manual and mechanical, with plot size being the primary factor for each growing operation. Large hop production areas traditionally utilize machinery capable of harvesting significant volumes of hop cones in a short time. However, the machinery can damage cone quality and requires very specific growing practices. Manual harvesting is more selective and capable of dealing with multiple maturity periods per plot, but it requires a higher input in labor costs. The following sections will discuss the pros and cons of each method to help decide which is best for each producer's individual needs (Miller 2017).

\section{Manual Harvesting}

Commonly used by small- and medium-scale hop producers, manual harvesting is traditionally used until the investment into mechanical harvesting can be made. Just as it sounds, manual harvesting involves the use of human labor to select and remove mature cones from the bines by hand. In smaller operations, it is common to use friends and family as volunteers, though there is truth in the saying "Never plant more hops than your volunteers can pick in a single day, because they won't come back for a second." In larger operations the use of paid farm laborers becomes more necessary. Within manual harvesting there are two commonly used variations, field and indoor manual harvesting. Regardless of the pickers and methods used, manual harvesting can be very labor intensive, requiring approximately six 10-hour days for a team of 12 pickers per acre of bines (Hops n.d.).

\section{Field Manual Harvesting}

The method most appropriate for beginning hop producers is field manual harvesting. With this method, the bines stay attached to their root balls, allowing the pickers to work directly in the field. The primary benefit of this method is that it generates the cleanest pick and the highest level of selectivity, whether using single or multiple cultivars per plot or single or multiple bines per string. Pickers can select only the mature cones while leaving the immature ones for a following harvest. Leaving the bines attached to their root balls also contributes more starch and sugar reserves to the rootstock for the following growing season. 
The disadvantage of this method is the mobility requirement, both in elevation and acreage. Hops are traditionally grown on 20-foot trellises made from steel wires strung between wooden poles, with cones reaching the top of the bines, so pickers commonly utilize ladders, cherry pickers or even stilts to reach the cones. This can be both dangerous and time consuming as the picker must constantly descend, move and re-ascend between strings. Figure 4 shows hop pickers in Kent, England, using tall poles as support for the hops, leaving the bine and pole still attached for removal and harvest. The UF/IFAS Research Hop Yard at the UF/ IFAS Mid-Florida Research and Education Center adopted a safer alternative method in which the bine training strings are attached to the support trellis wires by metal S hooks, rather than being tied to them directly. By using a magnet attached to the end of a telescoping pole, the training strings and attached bines can be lowered and re-hung for easy access while harvesting.

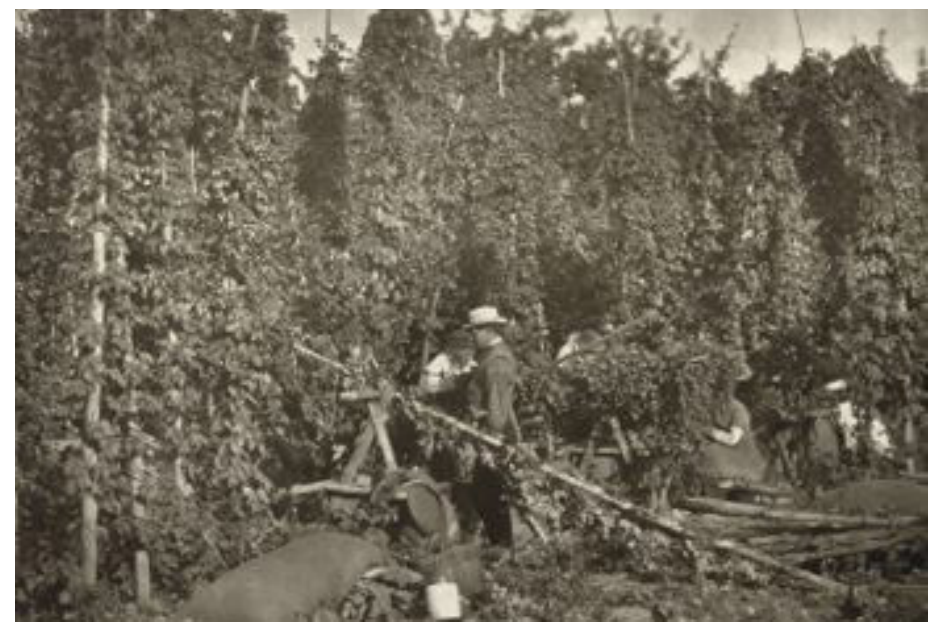

Figure 4. Hop-picking in Kent, England, 1875.

Credits: Stephen Thompson, courtesy of the British Library, London

\section{Indoor Manual Harvesting}

A hybrid between field manual harvesting and mechanical harvesting, indoor manual harvesting involves removing whole bines from the field and hand harvesting in an indoor facility. Because the bine is removed, this method has less selectivity than field manual harvesting, as premature cones can't be left for follow-up harvests. However, this method is still cleaner and more selective than mechanical harvesting. Traditionally, the bines are first cut at the base, separating them from the root ball and leaving them hanging from the trellis wires. Next, the hanging bines are separated from the support trellis and laid on trucks or wagons for transport to the indoor facility. While the large hop production areas use machinery to accomplish this, these steps are primarily done by hand in most operations.
Moving the bines to an indoor facility has multiple benefits, but the primary one is the environmental conditions for the pickers and the cones. Most facilities are not climate controlled but are covered from the sun, lowering the temperature. Picking tables can also be constructed at a convenient height for the pickers to stand on either side and work. Thus, indoor manual harvesting is capable of cleanly and selectively removing the cones from large numbers of bines while reducing worker environmental exposure.

\section{Machine Harvesting}

As hop production acreage increases, manual harvesting during the short maturity period available becomes significantly more difficult, and it becomes necessary to use mechanical harvesting machines. As with indoor manual harvesting, the bines are separated from the root ball at the bottom before being lowered from the support trellis at the top. For stationary harvesting machines, this is done primarily by hand, with bines loaded onto trucks or wagons for transport to the machine. For mobile harvesting machines, all necessary steps are primarily mechanized and performed directly in the field.

Whether stationary or mobile, most mechanical hop harvesters work on the same basic principle. Whole bines are hung between a series of revolving wheels with serrated wire teeth that strip the cones, leaves and stems from the bines underneath. This mixture is then separated by a series of forced air streams, sifting screens and dribble belts that distinguish the cones from the unwanted material (Figure 5). A secondary manual separation process is often required to remove any excess material missed by these steps. While very rapid, this violent process can negatively affect cone quality, primarily through the loss of the valuable lupulin glands. Large-scale hop producers generally make up for this quality loss with sheer volume (Kneen 2001).

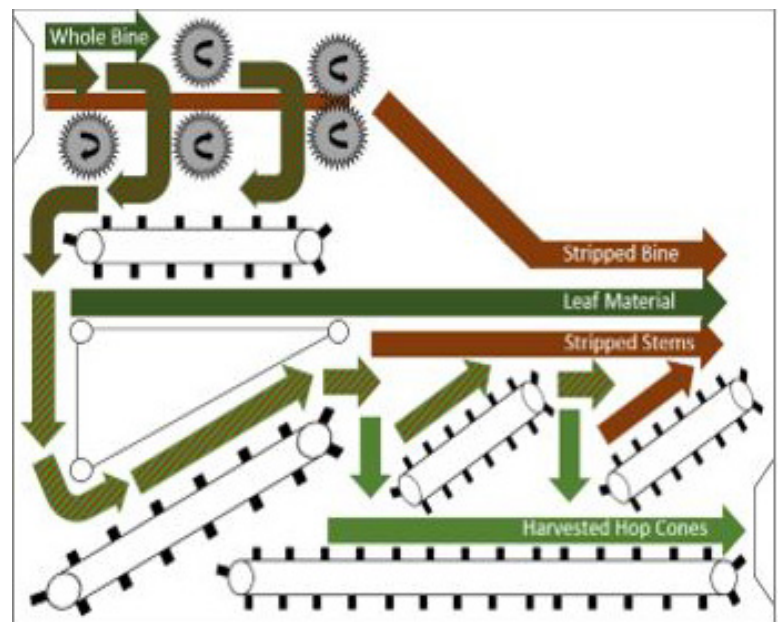

Figure 5. Hop harvester schematic. Credits: Sean M. Campbell, UF/IFAS 


\section{Harvesting Machines}

Selection of a proper Hopfenpfluckmaschine, literally translated from German as "hop-plucking machine," can be crucial for a growing hop producer (Figure 6). Factors such as mobility, productivity and new vs. used equipment should be considered when making the decision. The Wolf Corporation, located in Poland, is a popular provider and offers several variations ranging from $\sim \$ 30,000$ to $\$ 300,000$, depending on the capabilities. Shipping and reconstruction costs are not included in the above price range. Because of these costs, hop producers have begun seeking alternatives, such as purchasing old equipment or building harvesters using plans available on the internet (Miller 2017).

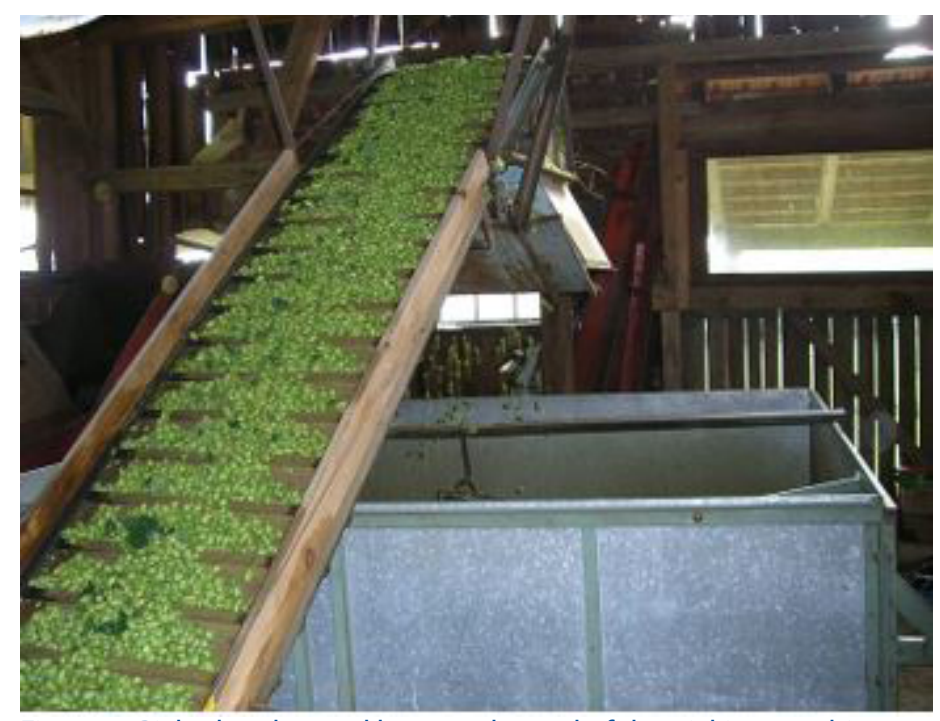

Figure 6. Picked and sorted hops at the end of the picking machine. Credits: Public domain, Wikimedia Commons

\section{Storage and Care}

Regardless of the method used, a critical factor of hops production to consider is storage and care of the cones during harvest. If left in a nonbreathable container, hops will begin to lose quality within an hour, primarily due to sweating and oxidation from the heat. While plastic buckets can be used for short periods (during manual harvest they can be attached directly to a ladder or belt for convenience), it is crucial that the cones be placed in burlap or other open-weaved material until processing. Hops should also be treated as a food commodity, with efforts made to keep them sanitary while harvesting. If animals are commonly found in the growing area and the bines are lowered during harvest, consider laying tarps to keep the bines off the ground.

\section{Conclusions}

The decision of which timing and method of hop harvesting to use must be made based on the wants and needs of the individual producer. As a new and smaller-scaled grower, it is recommended to start with field manual harvesting. But as acreage expands, so does the need for mechanization; a 2015 analysis of the manual vs. mechanical harvesting of sugarcane reported the manual harvest price to be almost double that of mechanical at $\$ 4.38 /$ ton and $\$ 2.41 /$ ton, respectively (Ahmed and Alam-Eldin 2015). Among producers seeking to benefit while avoiding the initial investment, a new trend has been the formation of cooperatives, where members split the cost and use of a mechanical hop harvester. While this is becoming increasingly popular, it is recommended that you attempt to stay within an hour of your harvester to avoid loss of quality and additional costs during transport. Whether on a small or large scale, it's up to the producer to do the research and determine which harvesting method is appropriate for their individual production needs.

\section{References}

Ahmed, A. E., and A. O. M. Alam-Eldin. 2015. "An Assessment of Mechanical vs Manual Harvesting of the Sugarcane in Sudan-The Case of Sennar Sugar Factory." Journal of the Saudi Society of Agricultural Sciences 14(2): 160-166.

Carter, P. R., E. A. Oelke, A. R. Kaminski, C. V. Hanson, S. M. Combs, J. D. Doll, G. L. Worf, and E. S. Oplinger. 2018. Hop, Alternative Field Crops Manual. University of Wisconsin Cooperative Extension Service.

Gorst Valley Hops. n.d. "Hop Harvesting and Processing: Harvesting to Drying to Processing-Methods Overview." PowerPoint Slideshow. https://jhawkins54.typepad.com/ files/hop-harvesting-and-processing-gorst-valley-hops.pdf.

Kneen, R. 2001. Small Scale \& Organic Hops Production. Left Fields BC.

Miller, S. 2017. FAQs for starting up a hop farm in New York. Cornell Cooperative Extension Madison County. 